\title{
Students' perception, attitudes, and readiness toward online learning in dental education in Saudi Arabia: a cohort study
}

This article was published in the following Dove Press journal:

Advances in Medical Education and Practice

\author{
Amal I Linjawi' \\ Lama S Alfadda ${ }^{2,3}$ \\ 'Department of Orthodontics, \\ Faculty of Dentistry, King Abdulaziz \\ University, Jeddah, Kingdom of Saudi \\ Arabia; ${ }^{2}$ Department of Advanced \\ General Dentistry, The Dental \\ Hospital, King Abdulaziz University, \\ Jeddah, Kingdom of Saudi Arabia; \\ ${ }^{3}$ Residency Program, Saudi Board \\ in Restorative Dentistry, Jeddah, \\ Kingdom of Saudi Arabia
}

Purpose: The purpose of this study was to assess students' perception, attitudes, and readiness toward online dental education in Saudi Arabia.

Materials and methods: This is a longitudinal study using a 5-point Likert scale questionnaire distributed to a cohort group of undergraduate dental students at King Abdulaziz University, Faculty of Dentistry, Jeddah, Saudi Arabia, during their fourth year (T1) and internship year (T2). It assessed technological access, computer skills, online skills, and motivation level in using e-learning for personal and learning purposes; and overall readiness for e-learning adoption in dental education. The response scale for each domain was categorized as follows: low readiness level (mean value $=1-<3$ ), acceptable/moderate readiness level (mean value $=3-<4$ ), and high readiness level (mean value=4-5). Descriptive and group comparisons were conducted using the chi-squared test, Fisher's exact test, and paired and independent samples $t$-test. The significance level was set at $P<0.05$.

Results: The respondents were as follows: T1 group ( $\mathrm{n}=72 ; 36$ males $[\mathrm{M}], 36$ females $[\mathrm{F}])$ and T2 group ( $\mathrm{n}=50 ; 20 \mathrm{M}, 30 \mathrm{~F}$ ). The results indicated high levels of computer skills, technology access, and perceived importance of online technology with no significant difference between the groups ( $P>0.05$ ). They also showed acceptable levels of e-learning experience and social influence on e-learning adoption with no significant difference between the groups $(P>0.05)$. A significant difference was reported in using e-learning for personal compared to learning purposes $(P<0.05)$. The T2 group reported significantly lower levels of online English literacy $(P<0.01)$, perceived impact of e-learning on dental education, and readiness for e-learning $(P<0.001)$. Multiple technical and content development supports were reported.

Conclusion: This study showed acceptable levels of individual characteristics and system competency levels as well as the perceived importance of using technology in dental education among the participants. However, the perceived impact of and readiness for e-learning were found to be less acceptable as students matured. The need for much support in some skills was also reported.

Keywords: e-learning, dental education, curriculum reform, online, technology

\section{Introduction}

E-learning had become an important method in education for its efficiency in providing education with lower costs, for ease of accessibility at any time and anywhere and for overcoming many traditional educational problems, such as lack of classrooms and a shortage of faculty. ${ }^{1-5}$ It has also been found to satisfy different learning styles, which is considered a major success factor in teaching and learning. ${ }^{1,4,5}$ Most higher education institutions are moving to implement online education in their programs. ${ }^{1,2}$
Department of Orthodontics, Faculty of Dentistry, King Abdulaziz University, PO Box 9066, Jeddah 214I3, Kingdom of Saudi Arabia

Tel +966504I5 5573

Email ailinjawi@kau.edu.sa 
Several e-learning and online learning tools and methods have been explored in the literature as effective tools and methods to expand the possibilities of teaching and learning in the health profession fields, including dental education. ${ }^{1-6}$ It has been undeniable that e-learning is equivalent to traditional classroom methods in regard to students' knowledge gain and performance. ${ }^{7-9}$ However, the influence of online learning methods on students' satisfaction, motivation, and self-assessment is greater when it is integrated with conventional methods. ${ }^{1,10}$ Students in health profession fields are required to gain and integrate theoretical and clinical knowledge in a suitable environment to become safe and competent health professionals. ${ }^{11}$ The importance of one-to-one supervision and hands-on training in such fields poses a challenge for e-learning curricula.

Web 2.0, including online discussion boards, wikis, blogs, and podcasts, comprises other e-learning tools that entail the added challenges of online social communication and collaboration skills as well as new media for creating and distributing knowledge. ${ }^{4,6,11}$ Such tools are known to be used in many institutions around the world as methods of virtual collaboration and for being sources for knowledge. ${ }^{11} \mathrm{Web}$ 2.0 tools make up the language of future generations. This mandates that educational institutions shift their educational paradigm from technology acceptance to instructional and pedagogical changes. In addition, institutional preparations, in regard to their technical, technological, and psychosocial capabilities and growth to cope with this trend, should be deeply investigated. ${ }^{4,6}$

The health profession educational fields, including dental education, demand high-quality educational methods. Saudi Arabia is also improving its educational goals and contributing to global educational changes to meet the challenges of coming generations. Under such moves, e-learning and online learning strategies will no longer be optional. However, difficulties and challenges will always surround any change, including but not limited to technological and social challenges. ${ }^{1,3,12-16}$

The Faculty of Dentistry at King Abdulaziz University in Jeddah, Saudi Arabia, is one of the largest colleges and has been accredited by many official bodies for its academic and health services. Thus, many studies and much effort have been undertaken to maximize the benefits of implementing online learning methods in its curriculum to meet the needs of globalization. This in turn mandates the need to assess and support students' level of technology access as well as their skills regarding online technology, communication, collaboration, and time management as an indirect way to support students' achievement in online learning. ${ }^{8,17}$
The students at King Abdulaziz University undergo a preparatory year before they join the dental school. During this year, most of the lectures are uploaded on Blackboard. Many courses are using virtual classrooms and conducting assignments through Blackboard. Students are required to use many software such as PowerPoint and Excel. Final exams are conducted using e-exam software. When they join the dental college, all the lectures and practical materials are uploaded on Blackboard. Some courses are using discussion boards and wikis. As in the preparatory year, most of the final exams are conducted through e-exam software.

This study was conducted to assess the perception, attitudes, and readiness of a cohort group toward the challenges of online learning in dental education in Saudi Arabia from 2014 to 2017 to assess potential support needs for online learning implementation in Saudi Arabia.

\section{Materials and methods Research design}

This is a longitudinal study that used a 5-point Likert scale questionnaire to evaluate changes in students' perception toward online learning implementation in dental education at King Abdulaziz University, Faculty of Dentistry (KAUFD), Jeddah, Saudi Arabia.

\section{Sample}

A cohort group of undergraduate dental students studying at KAUFD were approached at two points in time: in 2014, when they were fourth-year undergraduates (T1), and in 2017, during their internship year (T2).

\section{Questionnaire design}

After conducting a thorough literature review ${ }^{1,12-16}$ regarding the assessment and success factors of e-learning in education, a detailed questionnaire was designed to assess six primary domains, each with multiple subdomains. The questionnaire was in English and consisted of 34 (5-point Likert scale) questions, five multiple-choice questions, and two open-ended questions. The domains and subdomains were designed as follows:

1. Individual characteristics domain: it included the following subdomains:

(a) Sample distribution: it included age and gender.

(b) Computer skills: it was designed to assess the participants' computer skills at multiple levels: basic, intermediate, and advanced computer skills, such as formatting documents and managing multimedia. 
(c) E-learning experience: it was designed to assess participants' previous experience with and participation in e-learning activities, including online courses, online examinations, and their attendance of workshops on e-learning.

2. System competency needs domain: it included the following subdomains:

(a) Technology accessibility: it was designed to assess the accessibility of the required technology for e-learning implementation in teaching and learning, including hardware, software, Internet, and mobile technology.

(b) Perceived ease of use: this subdomain was designed to assess and compare participants' perceptions concerning the ease of using online tools for two different purposes: personal and learning. The subdomain included the following variables:

(i) Online skills: it was designed to assess participants' perceived skills with using different online services and tools, including search engines, synchronous and asynchronous communication tools, social media, collaborative Web 2.0 tools, as well as ability to manage time due dates.

(ii) Motivation level: the participants' perceived motivational level in using the Web and online tools for learning was assessed through the following variables: a) working on large projects individually; b) achieving goals and managing distractions; c) meeting deadlines; and d) spending long hours working online on tasks.

(iii) English literacy in online communication: the mother language of most of the participants was Arabic, although the dental subjects are taught in English at KAUFD. Thus, English language was thought to be a barrier that might affect participants' motivation to use online tools in their teaching and learning. Under this assumption, participants' perception of their English literacy in the context of online communication was assessed in this section.

(c) Perceived usefulness

(i) Importance of online technology to the participants' success in their education: this variable was also assessed and compared across two different purposes: personal and learning.

(ii) Impact of e-learning on dental education: it was designed to assess participants' ratings concerning the level of impact of e-learning on dental education.
3. Social influence domain or social norms: it was designed to assess the influence of others, including peers, family, and instructors, on participants' perception and use of online services. This variable was also assessed and compared for across different purposes: personal and learning.

4. Institutional support domain: it was designed to assess the importance of quick technical and administrative institutional support in the success of adopting e-learning in dental education.

5. Overall readiness domain: it was designed to assess participants' perceptions of their overall readiness for implementing e-learning in their educational field.

6. Needed technical support domain: it was designed to assess the technical support required by participants to adopt e-learning strategies in dental education. Multiple technical support items were assessed: basic computer skills (typing and editing), advanced computer skills, managing multimedia content, using the Web and online tools in education, designing online content, online communication skills, time management, and others.

The two open-ended questions were designed to explore further challenges that might be faced in adopting e-learning in dental education and suggested solutions and recommendations for overcoming these challenges.

\section{Methods of assessment}

A total of 200 questionnaires were distributed to the intended target sample as follows: 100 questionnaires were distributed to the group at $\mathrm{T} 1$ and 100 more questionnaires were given to the same cohort group at T2. The aim of the study and the questionnaire instructions were explained to the participants both verbally and in writing.

Informed consent included a person voluntarily agreeing to participate in the research study after being fully informed verbally with study staff, followed by documentation in a written and signed informed consent form. The responses were then collected, and the data were analyzed. Questionnaires with more than two missing responses for a given question were excluded.

\section{Statistical analyses}

Data from the subdomains in each domain were grouped, and mean values were calculated to represent the readiness levels for the specified subdomains. The scale for interpreting the readiness level was designed to mirror the interpretation of the 5-point Likert scale arrangement used for all questions 
in the questionnaire. Accordingly, the readiness scale was set as follows:

- Low readiness level: if the mean value for the domain ranged from 1 to $<3$.

- Acceptable/moderate readiness level: if the mean value for the domain ranged from 3 to $<4$.

- High readiness level: if the mean value for the domain ranged from 4 to 5 .

Descriptive statistics were generated for data reporting. Pearson chi-squared test, Fisher's exact test, paired-sample $t$-test, and independent-samples $t$-test were further used as indicated to examine differences in responses between the groups. The normality assumption was tested using Levene's test for homogeneity of variance. The results were analyzed using SPSS Release 16.0 for Windows 7. (SPSS Inc., Chicago, IL, USA). The significance level was set at $P<0.05$.

\section{Results}

Out of the 100 questionnaires distributed in 2014, the response rate was $72 \%(n=72)$, and out of the 100 questionnaires distributed in 2017 , the response rate was $50 \%(n=50)$.

\section{Questionnaire validity}

The internal reliability of the questionnaire was assessed by a test-retest method. A total of 20 participants were given the questionnaire twice with 2 -week interval. The test-retest reliability of the questionnaire was high with Pearson's coefficient of 0.80 .

\section{Individual characteristics domain Sample distribution}

The mean age was 24 years (range 23-26 years) at T1 and 25 years (range 24-29 years) at T2. No significant difference in gender distribution was reported between the two groups assessed $(P>0.05$; Table 1$)$.

\section{Computer skills}

Results indicated a high readiness level in computer skills in both groups (mean: $\mathrm{T} 1=4.13 \pm 0.71 ; \mathrm{T} 2=4.27 \pm 0.64$ ). Independent-samples $t$-test further indicated no significant difference between the groups ( $P>0.05$; Table 1$)$.

\section{E-learning experience}

Most of the participants in both groups reported that they had previous experience with online tools and education (80.6\% from T1 group [n=58] and 78\% from T2 group $[\mathrm{n}=39])$, with no significant difference between the groups (P>0.05; Table 1).

\section{System competency needs domain Technology accessibility}

Results indicated a high level of technological accessibility for both groups (mean: $\mathrm{T} 1=4.06 \pm 0.78$; $\mathrm{T} 2=4.25 \pm 0.67$ ), with no significant difference between the groups $(P>0.05$; Table 2).

\section{Perceived ease of use \\ Online skills}

The mean scores for online skills for personal purposes were $4.14( \pm 0.74)$ for $\mathrm{T} 1$ and $4.02( \pm 0.87)$ for T2, indicating a high level of online skills among all participants, with no significant difference between the groups $(P>0.05)$. For learning purposes, the mean scores were $3.83( \pm 0.93)$ for $\mathrm{T} 1$ and 3.67 $( \pm 1.25)$ for $\mathrm{T} 2$, indicating an acceptable level of online skills, with no significant difference between the groups $(P>0.05)$. Paired-sample $t$-test further indicated a significant difference in online skills between the two purposes of usage $(P<0.001)$ in both groups (Table 2).

\section{Motivation level}

The mean scores for motivation level when using online tools for personal purposes were $3.60( \pm 0.88)$ for $\mathrm{T} 1$ and $3.51( \pm 1.05)$ for $\mathrm{T} 2$, and for learning purposes, they were $3.38( \pm 0.90)$ for $\mathrm{T} 1$ and $3.30( \pm 1.14)$ for $\mathrm{T} 2$, indicating an acceptable motivation level for both purposes, with no significant difference between the two groups. However, paired-sample $t$-test indicated a significant difference in the motivation level between the two purposes of use $(P<0.05)$ in both groups (Table 2).

\section{English literacy in online communication}

The mean scores for online English literacy readiness level for personal purpose were $4.31 \pm 0.88$ for $\mathrm{T} 1$ and $3.62 \pm 1.51$ for T2, indicating a high readiness level for the T1 group and an acceptable level for the T2 group. For learning purposes, they were $4.11( \pm 1.15)$ for T1 and $3.32( \pm 1.62)$ for T2, also indicating a high readiness level for the T1 group and an acceptable level for the T2 group. Independent-samples $t$-test indicated that the T2 group was significantly lower in online English literacy readiness than the T1 group across both purposes of usage $(P<0.01)$. Paired-sample $t$-test further indicated no significant difference in online English literacy for the $\mathrm{T} 1$ group between the two purposes of usage $(P>0.05)$, whereas a significant difference between the two 
Table I Distribution of responses to "individual characteristics domain" (mean, range, number, and percentage) for the two study groups

\begin{tabular}{|c|c|c|c|}
\hline \multicolumn{2}{|l|}{ Variables } & \multicolumn{2}{|l|}{ Groups } \\
\hline & & \multirow{2}{*}{$\begin{array}{l}\text { TI (fourth year), } n=72 \\
24.12 \\
\end{array}$} & \multirow{2}{*}{$\begin{array}{l}\mathbf{T 2} \text { (internship), } \\
\mathbf{n = 5 0} \\
25.12 \\
\end{array}$} \\
\hline Age, years & Mean & & \\
\hline & Range & $23-26$ & $24-29$ \\
\hline \multirow[t]{3}{*}{ Gender } & M & $36(50 \%)$ & $20(40 \%)$ \\
\hline & $\mathrm{F}$ & $36(50 \%)$ & $30(60 \%)$ \\
\hline & Significance between groups $(P<0.05)$ & 0.276 & \\
\hline \multirow[t]{3}{*}{ Computer skills } & Mean & 4.13 & 4.27 \\
\hline & SD & 0.71 & 0.64 \\
\hline & Significance between groups $(P<0.05)$ & $0.25 I$ & \\
\hline \multirow[t]{4}{*}{ E-learning experience } & Missing & 0 & $3(6 \%)$ \\
\hline & No experience & $14(19.4 \%)$ & $8(16 \%)$ \\
\hline & Have experience & $58(80.6 \%)$ & $39(78 \%)$ \\
\hline & Significance between groups $(P<0.05)$ & \multicolumn{2}{|l|}{0.103} \\
\hline
\end{tabular}

Note: Significance level was set at $P<0.05$.

Abbreviations: $\mathrm{M}$, males; $\mathrm{F}$, females.

purposes of usage was reported for the T2 group $(P<0.05$; Table 2).

\section{Perceived usefulness}

Importance of online technology to participants' success

The mean scores for the perceived importance of online technology for personal use were $4.33( \pm 1.02)$ for $\mathrm{T} 1$ and $4.16( \pm 1.28)$ for $\mathrm{T} 2$, and for learning usages, they were 4.19 $( \pm 1.16)$ for $\mathrm{T} 1$ and $4.12( \pm 1.42)$ for $\mathrm{T} 2$. Thus, the perceived importance of online technology was high among all participants for both purposes of usage in both groups. Pairedsample $t$-test indicated no statistically significant difference in the perceived importance of online technology between the two purposes of usage $(P>0.05)$ in both groups (Table 2$)$.

Impact of e-learning on dental education

More than half of the T1 group $(68 \%, n=49)$ reported that e-learning had an impact on dental education. On the other hand, $84 \%(n=42)$ of the T2 group reported that e-learning had no impact on dental education. Fisher's exact test indicated a highly significant difference between the groups in their perception of the impact of e-learning on dental education $(P<0.001$; Table 2$)$.

\section{Social influence domain}

Mean scores for the social influence on using online technology for personal purposes were $3.98( \pm 0.98)$ for $\mathrm{T} 1$ and $3.77( \pm 1.19)$ for $\mathrm{T} 2$, whereas for learning purposes, the mean scores were $3.89( \pm 1.07)$ for $\mathrm{T} 1$ and $3.76( \pm 1.29)$ for
T2, indicating an acceptable level of social influence, with no significant difference between the two groups or between the two purposes of usage $(P>0.05)$ in both groups (Table 3$)$.

\section{Institution support domain}

Mean scores for institutional support in using online technology for personal purposes were $4.29( \pm 0.98)$ for $\mathrm{T} 1$ and $3.98( \pm 1.25)$ for $\mathrm{T} 2$, whereas for learning purposes, the mean scores were $4.20( \pm 0.99)$ for T1 and $3.88( \pm 1.39)$ for T2. These results, thus, reflect a high level of importance of institutional support for e-learning implementation for the T1 group and a moderate level of importance of institutional support for e-learning implementation for the T2 group, with no significant difference between the two groups or between the two purposes of usage $(P>0.05)$ in both groups (Table 4).

\section{Overall readiness domain}

Almost half of the T1 group $(47.2 \%, n=34)$ reported that they were ready for e-learning adoption in dental education. On the other hand, $66 \%(n=33)$ of the T2 group reported a low level of readiness for e-learning adoption in dental education. Fisher's exact test indicated a highly significant difference between the groups in their readiness for e-learning in dental education $(P<0.001$; Table 5$)$.

\section{Needed technical support domain}

The technical support most demanded by the T1 group was in the following areas: advanced computer skills ( $n=33 / 72$, 
Table 2 Distribution of responses to "system competency needs domain" (mean, SD, and percentage) for the two study groups

\begin{tabular}{|c|c|c|c|c|c|c|}
\hline \multicolumn{3}{|l|}{ Variables } & \multicolumn{2}{|l|}{ Groups } & \multirow{3}{*}{$\begin{array}{l}\text { Total } \\
(N=\mid 22)\end{array}$} & \multirow{3}{*}{$\begin{array}{l}\text { Significance } \\
\text { (between } \\
\text { groups), } P<0.05\end{array}$} \\
\hline & & & \multirow{2}{*}{$\begin{array}{l}\text { TI (fourth } \\
\text { year), } n=72\end{array}$} & \multirow{2}{*}{$\begin{array}{l}\text { T2 } \\
\text { (internship), } \\
\mathbf{n}=\mathbf{5 0} \\
4.25 \pm 0.67\end{array}$} & & \\
\hline $\begin{array}{l}\text { Technology } \\
\text { accessibility }\end{array}$ & & Mean (SD) & & & & \\
\hline \multicolumn{7}{|c|}{ Perceived ease of use } \\
\hline \multirow[t]{3}{*}{$\begin{array}{l}\text { Skills in using } \\
\text { online tools }\end{array}$} & $\begin{array}{l}\text { Personal } \\
\text { purposes }\end{array}$ & Mean (SD) & $4.14 \pm 0.74$ & $4.02 \pm 1.03$ & $4.09 \pm 0.87$ & 0.440 \\
\hline & $\begin{array}{l}\text { Learning } \\
\text { purposes }\end{array}$ & Mean (SD) & $3.83 \pm 0.93$ & $3.67 \pm 1.25$ & $3.76 \pm 1.07$ & 0.424 \\
\hline & \multicolumn{2}{|c|}{$\begin{array}{l}\text { Significance within groups } \\
(P<0.05)\end{array}$} & 0.001 & 0.001 & 0.000 & \\
\hline \multirow{3}{*}{$\begin{array}{l}\text { Motivation level } \\
\text { in using online } \\
\text { tools }\end{array}$} & $\begin{array}{l}\text { Personal } \\
\text { purposes }\end{array}$ & Mean (SD) & $3.60 \pm 0.88$ & $3.5 I \pm 1.05$ & $3.56 \pm 0.95$ & 0.617 \\
\hline & $\begin{array}{l}\text { Learning } \\
\text { purposes }\end{array}$ & Mean (SD) & $3.38 \pm 0.90$ & $3.30 \pm 1.14$ & $3.34 \pm 1.0$ & 0.702 \\
\hline & \multicolumn{2}{|c|}{$\begin{array}{l}\text { Significance within groups } \\
(P<0.05)\end{array}$} & 0.007 & 0.022 & 0.000 & \\
\hline \multirow{3}{*}{$\begin{array}{l}\text { English literacy } \\
\text { in online } \\
\text { communication }\end{array}$} & $\begin{array}{l}\text { Personal } \\
\text { purposes }\end{array}$ & Mean (SD) & $4.3 I \pm 0.88$ & $3.62 \pm|.5|$ & $4.02 \pm 1.22$ & 0.005 \\
\hline & $\begin{array}{l}\text { Learning } \\
\text { purposes }\end{array}$ & Mean (SD) & $4.11 \pm 1.15$ & $3.32 \pm 1.62$ & $3.79 \pm 1.42$ & 0.004 \\
\hline & \multicolumn{2}{|c|}{$\begin{array}{l}\text { Significance within groups } \\
(P<0.05)\end{array}$} & 0.061 & 0.021 & 0.003 & \\
\hline \multicolumn{7}{|c|}{ Perceived usefulness } \\
\hline \multirow[t]{3}{*}{$\begin{array}{l}\text { Importance of } \\
\text { online technology }\end{array}$} & $\begin{array}{l}\text { Personal } \\
\text { purposes }\end{array}$ & Mean (SD) & $4.33 \pm 1.02$ & $4.16 \pm 1.28$ & $4.26 \pm 1.13$ & 0.409 \\
\hline & $\begin{array}{l}\text { Learning } \\
\text { purposes }\end{array}$ & Mean (SD) & $4.19 \pm 1.16$ & $4.12 \pm 1.42$ & $4.16 \pm 1.27$ & 0.751 \\
\hline & \multicolumn{2}{|c|}{$\begin{array}{l}\text { Significance within groups } \\
(P<0.05)\end{array}$} & 0.167 & 0.642 & 0.152 & \\
\hline \multirow{4}{*}{$\begin{array}{l}\text { Impact of e-learning } \\
\text { on dental education }\end{array}$} & \multicolumn{2}{|c|}{ Missing } & $9 / 72(12.5 \%)$ & $3 / 50(6 \%)$ & $12 / 122(9.8 \%)$ & \multirow[t]{4}{*}{0.000} \\
\hline & \multicolumn{2}{|l|}{ Not sure } & $2 / 72(2.8 \%)$ & $5 / 50(10 \%)$ & $7 / 122(5.6 \%)$ & \\
\hline & \multicolumn{2}{|c|}{ No impact } & $\begin{array}{l}12 / 72 \\
(16.7 \%) \\
\end{array}$ & $42 / 50(84 \%)$ & $54 / 122(44.3 \%)$ & \\
\hline & \multicolumn{2}{|c|}{ Have an impact } & $\begin{array}{l}49 / 72 \\
(68.1 \%)\end{array}$ & $0 / 50(0 \%)$ & $49 / 122(40.2 \%)$ & \\
\hline
\end{tabular}

Note: Significance level was set at $P<0.05$.

Table 3 Distribution of responses to "social influence domain" (mean and SD)

\begin{tabular}{|c|c|c|c|c|c|c|}
\hline \multicolumn{3}{|c|}{ Variables } & \multicolumn{2}{|l|}{ Groups } & \multirow{2}{*}{$\begin{array}{l}\text { Total } \\
(\mathbf{N}=122)\end{array}$} & \multirow{2}{*}{$\begin{array}{l}\text { Significance } \\
\text { (between groups), } \\
P<0.05\end{array}$} \\
\hline & & & $\begin{array}{l}\text { TI (fourth } \\
\text { year), } n=72\end{array}$ & $\begin{array}{l}\text { T2 } \\
\text { (internship), } \\
n=50\end{array}$ & & \\
\hline \multirow{3}{*}{$\begin{array}{l}\text { Social } \\
\text { influence }\end{array}$} & Personal purposes & Mean (SD) & $3.98 \pm 0.98$ & $3.77 \pm 1.19$ & $3.89 \pm 1.07$ & 0.295 \\
\hline & Learning purposes & Mean (SD) & $3.89 \pm 1.07$ & $3.76 \pm 1.29$ & $3.84 \pm 1.17$ & 0.557 \\
\hline & \multicolumn{2}{|c|}{ Significance within groups $(P<0.05)$} & 0.305 & 0.930 & 0.357 & \\
\hline
\end{tabular}

Note: Significance level was set at $P<0.05$.

$45.83 \%)$, using the Web $(\mathrm{n}=35 / 72,48.61 \%)$ and online tools $(\mathrm{n}=39 / 72,54.17 \%)$ in education, and time management ( $\mathrm{n}=42 / 72,58.33 \%)$. On the other hand, the technical support most demanded by the T2 group was in the following areas: using online tools in education $(n=39 / 72$,
$54.17 \%)$, designing online content $(\mathrm{n}=28 / 50,56 \%)$, and time management $(n=33 / 50,66 \%)$. The chi-squared test further indicated no significant difference between the groups regarding the different types of technical support needed $(P>0.05$; Figure 1$)$. 
Table 4 Distribution of responses to "institutional support domain" (mean and SD) for the two study groups

\begin{tabular}{|c|c|c|c|c|c|c|}
\hline \multicolumn{3}{|l|}{ Variables } & \multicolumn{2}{|l|}{ Groups } & \multirow{2}{*}{$\begin{array}{l}\text { Total } \\
(N=\mid 22)\end{array}$} & \multirow{2}{*}{$\begin{array}{l}\text { Significance } \\
\text { (between groups), } \\
P<0.05\end{array}$} \\
\hline & & & $\begin{array}{l}\text { TI (fourth } \\
\text { year), } n=72\end{array}$ & $\begin{array}{l}\text { T2 } \\
\text { (internship), } \\
n=50\end{array}$ & & \\
\hline \multirow{3}{*}{$\begin{array}{l}\text { Institutional } \\
\text { support }\end{array}$} & Personal purposes & Mean (SD) & $4.28 \pm 0.98$ & $3.98 \pm 1.25$ & $4.16 \pm 1.06$ & 0.128 \\
\hline & Learning purposes & Mean (SD) & $4.20 \pm 0.99$ & $3.88 \pm 1.39$ & $4.07 \pm 1.17$ & 0.120 \\
\hline & \multicolumn{2}{|c|}{ Significance within groups $(P<0.05)$} & 0.402 & 0.322 & 0.198 & \\
\hline
\end{tabular}

Note: Significance level was set at $P<0.05$.

Table 5 Distribution of responses to "overall readiness domain" (number and percentage) for the two study groups

\begin{tabular}{|c|c|c|c|c|}
\hline \multicolumn{2}{|l|}{ Variables } & \multicolumn{2}{|l|}{ Groups } & \multirow{2}{*}{$\begin{array}{l}\text { Significance } \\
\text { (between groups), } \\
P<0.05\end{array}$} \\
\hline & & $\begin{array}{l}\text { TI (fourth year), } \\
\mathrm{n}=72\end{array}$ & $\begin{array}{l}\text { T2 (internship), } \\
n=50\end{array}$ & \\
\hline \multirow[t]{4}{*}{ Overall readiness } & Missing & I I/72 (I 5.3\%) & $2 / 50(4 \%)$ & \multirow[t]{4}{*}{0.000} \\
\hline & Not ready & $7 / 72$ (9.7\%) & $15 / 50(30 \%)$ & \\
\hline & A bit ready & $20 / 72(27.8 \%)$ & $33 / 50(66 \%)$ & \\
\hline & Ready & $34 / 72(47.2 \%)$ & $0 / 50(0 \%)$ & \\
\hline
\end{tabular}

Note: Significance level was set at $P<0.05$.

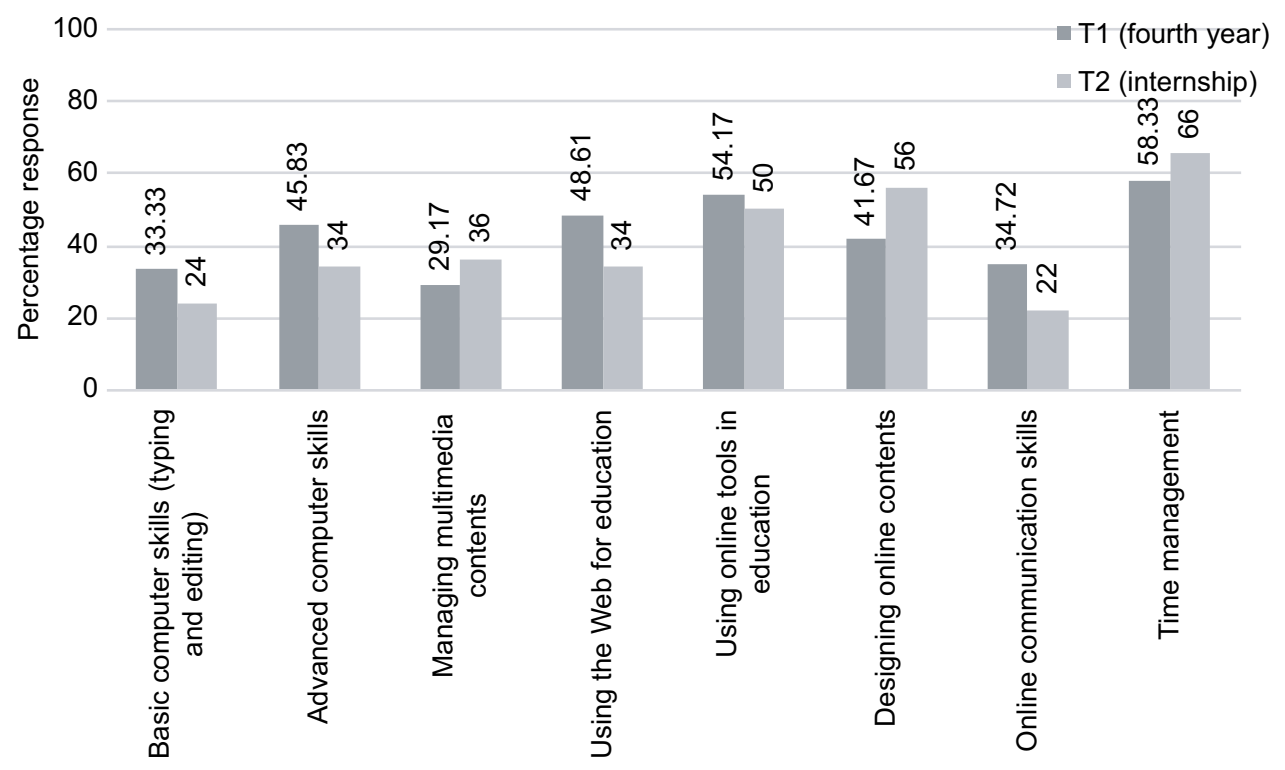

Figure I Distribution of responses (percentages) to "the different technical support needs" for the two study groups. Note: Significance level was set at $P<0.05$.

\section{Discussion}

The current study assessed the perception, attitudes, and readiness of a cohort group toward the challenges of online learning in dental education in Saudi Arabia. The participants in the current study reported a high level of computer skills and adequate e-learning experience. These individual characteristics were maintained in both study groups. Similar results were also reported by Asiry ${ }^{3}$ in a sample of undergraduate dental students from King Saud University. Results of these two studies, both conducted in two primary institutions in Saudi Arabia, suggest that dental students in Saudi Arabia are ready for e-learning adoption from a technological skill point of view.

The success of e-learning adoption is also highly dependent on technological accessibility and having a good Internet connection. ${ }^{4,10,15}$ The dental students from KAUFD 
who participated in the current study and the dental students from King Saud University, Riyadh, reported high levels of technology accessibility, assuring the presence of a good technological foundation for e-learning adoption in the primary institutions in Saudi Arabia. ${ }^{3}$ Participants also reported an acceptable level of online skills and motivation level for using online tools, but they preferred using such tools for personal uses rather than for learning purposes. The participants also reported greater perceived confidence levels for English literacy in using online tools when they were in their fourth year of undergraduate training than when they were in their internship year. The nature of e-learning adoption at KAUFD changes as students progress to higher levels. In the preparatory level, students were mostly listeners and e-learning contents were mainly static. While at their fifth and sixth dental years, the e-learning interactions and activities move to discussion forums, Blogs and assignments that require greater communication skills and language proficiency. This might be a factor in the reported changes of students' perception toward online English literacy confidence level. Such changes in confidence might also reflect the changes in maturity and feelings of responsibility, and it also needs further investigation. Findings also indicated that the participants did not perceive the ease of using online tools for learning purposes in the same way that they perceived the ease of using them for personal purposes. Similar findings were also reported by Alsuraihi et al, ${ }^{16}$ who assessed students' online skills in medical education. The authors of this study consider the language barrier in using online tools in dental education to be an important issue that needs support and management.

Paechter et $\mathrm{al}^{8}$ found that students' expectations for and experiences with e-learning are directly related to their learning achievements and course satisfaction. Participants in the current study perceived that online technology is highly important for both personal and learning purposes. However, their attitudes toward the impact of such tools on dental education changed over time. They perceived that e-learning had a great impact on dental education when they were in their fourth year, whereas, in their internship year, they considered it to have no impact. These results, thus, suggest that the usefulness of online tools in dental education might not be clear to the participants. Such a finding is in disagreement with many other studies that have reported a positive impact of e-learning on dental education. ${ }^{3,16}$ Asiry $^{3}$ assessed static online content via Twitter and reported positive perceived impacts on education. Alsuraihi et al ${ }^{16}$ also assessed social media and reported perceived positive impacts. By contrast, the current study focused on assessing major soft skills for handling online tools in education, such as properly using search engines, synchronous and asynchronous communication tools, social media, collaborative Web 2.0 tools, the ability to manage time and due dates, working on large projects individually, achieving goals and managing distractions, meeting deadlines, and spending long hours working online on tasks. Such in-depth analysis of the skills required to succeed in online learning showed that students still need a lot of support and guidance when incorporating online tools into education. ${ }^{4}$

Social influence is a hidden factor behind the users' attitudes toward and use of technology. ${ }^{4,13}$ The social influence on online tool use in the current study was found to be acceptable and not too high, as reported by the participants at all levels.

The institutional support for e-learning implementation was reported to be important by the participants at all levels. The top-down implementation from the administrative level down to the user level was reported to be an important and more sustainable strategic movement. ${ }^{1,4,13,16,18}$

The skills enhancement and development program for educators and learners to use the technology in education is an important factor for the success of e-learning. ${ }^{4,13,16,18,19}$ The technical support most demanded by the participants at all levels in the current study concerned how to use online tools in education and time management. The internship group also reported support needs centering on how to design online content. Such findings merit attention and careful planning by e-learning leaders., ${ }^{4,16,18}$

E-learning and online learning adoption and implementation in dental education are no longer in question, as e-learning is the platform for education in the coming era. ${ }^{20}$ However, assessing and supporting learners' needs are major concerns for achieving educational learning outcomes and graduating competent learners. ${ }^{4,18}$ Findings from the current study show multiple important factors to consider when planning e-learning implementation in dental education. Other factors, including organizational, economic, and cultural issues, also need to be further explored, particularly when assessing the institutional capacity to cope with the changing demands in education.

\section{Conclusion}

This study showed acceptable levels of individual characteristics and system competency levels as well as the perceived importance of using online technology in dental education among the participants.

Multiple studies conducted in Saudi Arabia have demonstrated the readiness of learners for e-learning adoption from a technological accessibility perspective. 
English literacy for using online tools, social influence, and institutional support are important hidden factors in e-learning implementation in dental education.

Participants reported better online skills and motivation level for using online tools for personal purposes than that for learning purposes.

The technical support most demanded by the participants included proper use of online tools in education, time management, and designing online content.

\section{Acknowledgment}

The abstract of this paper was presented at the Advancing Excellence in Dental Education Conference (SDES 2017), Princess Nourah Bint Abdulrahman University, Riyadh, Saudi Arabia, as a poster presentation with interim findings. The poster's abstract was published in the conference proceedings.

\section{Disclosure}

The authors report no conflicts of interest in this work.

\section{References}

1. George PP, Papachristou N, Belisario JM, et al. Online eLearning for undergraduates in health professions: A systematic review of the impact on knowledge, skills, attitudes and satisfaction. J Glob Health. 2014;4(1):1-17.

2. Allen IE, Seaman J. Going the Distance: Online Education in the United States, 2011. Newburyport (MA): Sloan Consortium; 2011.

3. Asiry MA. Dental students' perceptions of an online learning. Saudi Dent J. 2017;29(4):167-170.

4. Linjawi AI, Walmsley AD, Hill KB. Online discussion boards in dental education: potential and challenges. Eur J Dent Educ. 2012;16(1):e3-e9.
5. Pahinis K, Stokes CW, Walsh TF, Tsitrou E, Cannavina G. A blended learning course taught to different groups of learners in a dental school: follow-up evaluation. J Dent Educ. 2008;72(9):1048-1057.

6. Cain J, Fox BI. Web 2.0 and pharmacy education. Am J Pharm Educ. 2009;73(7):120.

7. Gormley GJ, Collins K, Boohan M, Bickle IC, Stevenson M. Is there a place for e-learning in clinical skills? A survey of undergraduate medical students' experiences and attitudes. Med Teach. 2009;31(1):e6-e12.

8. Paechter M, Maier B, Macher D. Students' expectations of, and experiences in e-learning: Their relation to learning achievements and course satisfaction. Comput Educ. 2010;54(1):222-229.

9. Santos GN, Leite AF, Figueiredo PT, et al. Effectiveness of E-Learning in Oral Radiology Education: A Systematic Review. J Dent Educ. 2016;80(9):1126-1139.

10. Sarsar F, Kaval ME, Klasser GD, Güneri P. Impact of internet supported dental education: Initial outcomes in a study sample. J Human Sci. 2016;13(3):4986-4997.

11. Boulos MNK, Maramba I, Wheeler S. Wikis, blogs and podcasts: a new generation of Web-based tools for virtual collaborative clinical practice and education. BMC Med Educ. 2006;6(1):1-8.

12. Al-Shehri AM. E-learning in Saudi Arabia: "To E or not to E, that is the question". J Family Community Med. 2010;17(3):147-150.

13. Al-Harbi KRAS. Investigating Factors Influencing the Adoption of E-learning: Saudi Students'Perspective. Leicester: University of Leicester; 2011.

14. Aljabre A. An exploration of distance learning in Saudi Arabian universities: Current practices and future possibilities. Int J Instruct Technol Distance Learn. 2012;9(2):21-28.

15. Al-Asmari AM, Rabb Khan MS. E-learning in Saudi Arabia: Past, present and future. Near and Middle Eastern J Res Educ. 2014;18(2014):2.

16. Alsuraihi AK, Almaqati AS, Abughanim SA, Jastaniah NA. Use of social media in education among medical students in Saudi Arabia. Korean J Med Educ. 2016;28(4):343-354.

17. Neville V, Lam M, Gordon CJ. The impact of eLearning on health professional educators' attitudes to information and communication technology. J Multidiscip Healthc. 2015;8:75.

18. Eaton KA, Reynolds PA, Grayden SK, Wilson NH. A vision of dental education in the third millennium. Br Dent J. 2008;205(5):261-271.

19. Doherty I, Sharma N, Harbutt D. Contemporary and future eLearning trends in medical education. Med Teach. 2015;37(1):1-3.

20. McAndrew M, Johnston AE. The role of social media in dental education. J Dent Educ. 2012;76(11):1474-1481.
Advances in Medical Education and Practice

\section{Publish your work in this journal}

Advances in Medical Education and Practice is an international, peerreviewed, open access journal that aims to present and publish research on Medical Education covering medical, dental, nursing and allied health care professional education. The journal covers undergraduate education, postgraduate training and continuing medical education

\section{Dovepress}

including emerging trends and innovative models linking education, research, and health care services. The manuscript management system is completely online and includes a very quick and fair peer-review system. Visit http://www.dovepress.com/testimonials.php to read real quotes from published authors. 